\title{
C-TO-V INCORPORATION AND SUBJECT RAISING ACROSS CP-BOUNDARY
}

\author{
YosHIKI OGAWA \\ Tohoku University
}

\begin{abstract}
The Subject Raising (SR) in Japanese is an A-movement across a CPboundary. It remains unclear why such a movement is possible without violating the Phase Impenetrability Condition. To answer this question, it is proposed in this article that the head of the embedded CP in the SR construction undergoes incorporation to the selecting $\mathrm{V}$. It is argued that this proposal not only solves the above mentioned problem but also account for (i) the otherwise systematic locality effects on A-movement in Japanese, (ii) the otherwise unexplained behavior of the indeterminate pronoun in the embedded subject position, and (iii) the fact that the embedded clause cannot have a temporal reference independent of the matrix clause.*
\end{abstract}

Keywords: C-to-V incorporation, Subject Raising, locality of A-movement, Phase Impenetrability Condition, EPP

\section{Introduction}

In Kuno (1976), it is argued that the alternation between (1a) and (1b) illustrates Subject Raising (henceforth, SR) phenomenon in Japanese:

( 1 ) a. John-ga [Mary-ga tensai-da to] John-Nom Mary-Nom genius-be Comp omot-tei-ru.

believe-Stat-Nonpast

'John believes Mary to be a genius.'

* I am grateful to two anonymous reviewers for invaluable comments and suggestions. All remaining errors and inadequacies are my own. This work is supported in part by a Grant-in-Aid for Young Scientists (B) from the Ministry of Education, Culture, Sports, Science and Technology, Grant No. 17720077.

English Linguistics 24: 1 (2007) 33-66 - 33-

(C) 2007 by the English Linguistic Society of Japan 


\section{b. John-ga [Mary- $\mathrm{O}_{\mathrm{i}}$ [ $t_{\mathrm{i}}$ tensai-da to $]$ John-Nom Mary-Acc genius-be Comp omot]-tei-ru. believe-Stat-Nonpast}

The embedded subject NP is in the (structural) Nominative Case in (1a), whereas it is in the Accusative Case in (1b). ${ }^{1}$ Kuno argues that the Accusative subject in (1b) undergoes raising operation to the matrix object position. Thus, (1b) is parallel to the English raising-to-object (RTO) construction in (2), which is also known as the "Exceptional Case marking" (ECM) construction (Postal (1974), Chomsky (1981)):

(2) John believes Mary to be smart.

As for the RTO construction in (2), various syntactic diagnostics including Binding Conditions (A), (B), and (C), and Quantifier Scope indicate that the embedded subject in the Accusative Case occupies the matrix object position at LF (Lasnik and Saito (1991), Wilder (1997)). Sakai (1996, 1998a) and Tanaka (2002) show that application of the same diagnostics to Japanese shows that the embedded subject in (1b), too, occupies the matrix object position at LF. Then, we are tempted to apply whatever analysis is valid for the RTO construction in English to the SR construction in Japanese.

However, one difference between (1b) and (2) keeps us from proceeding along these lines: while the embedded clause in (2) is usually assumed to be IP (Chomsky (1981)), ${ }^{2}$ the embedded clause in (1b) is $\mathrm{CP}$, headed by the complementizer to. $^{3}$ If $\mathrm{SR}$ is a movement to the matrix object position, which is an A-position, and if it crosses the $\mathrm{CP}$ boundary, then we have to ask why such a movement is possible.

1 In what follows, (unless specifically noted,) we will use the capital notation of 'Case', without distinguishing 'abstract Case' and 'morphological case,' since we can assume for our purposes that an NP in a certain morphological case (Nom/Acc) must always have its corresponding abstract Case feature (Nom/Acc) checked (or valued) by the relevant functional head. But see Aoyagi (2006) for a different view.

2 Pesetsky (1995), Ormazabal (1995) and Ogawa (2001) argue that the ECM complement in English is also CP headed by the empty complementizer. However, we assume for simplicity that it is IP. See also note 22 .

3 Several researchers claim or assume that this element is not the functional category of complementizer but a quotative particle (Fukui (1986), Sakai (1998a), Kawai (2006)). However, we assume, with Kaneko (1988), Ohta (1997), Hiraiwa (2001) and Tanaka (2002), that it is a complementizer. 
Chomsky $(2000,2001)$ proposes that movement is subject to (3):

( 3 ) Phase Impenetrability Condition (PIC):

In phase $\alpha$ with head $\mathrm{H}$, the domain of $\mathrm{H}$ is not accessible to operation outside $\alpha$, only $\mathrm{H}$ and its edge are accessible to such operations. (Chomsky (2000: 108))

Suppose that the matrix object position is [Spec, v] and that $\mathrm{C}$ and the transitive $\mathrm{v}$ (which is represented as $\mathrm{v}^{*}$ ) are the (strong) phase heads. Then, at the point when phrase structure is constructed up to $\mathrm{v}^{*} \mathrm{P}$, the probe $\mathrm{v}^{*}$ can have access to the edge of $\mathrm{CP}$, but not into the domain of the phase head. This means that in (4), WP is visible for $\mathrm{v}^{*}$, but neither $\mathrm{ZP}$ nor $\mathrm{KP}$ is:

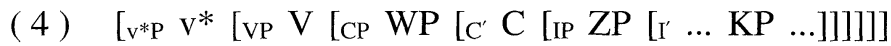

Now that the embedded subject in (1b) corresponds to $\mathrm{ZP}$ in (4), it should be invisible from the matrix $\mathrm{v}^{*}$.

One might argue that the embedded subject is raised to the embedded [Spec, C] for some reason (Kaneko (1988)). However, if the embedded subject has to be ultimately raised to the matrix object position, the movement to the embedded [Spec, C] should not be allowed, since movement from an A-position to an $\mathrm{A}^{\prime}$-position and back to an A-position inevitably leads to improper movement. To avoid this conclusion, one might assume, as Tanaka (2002) does, that [Spec, C] is exceptionally an A-position here. Alternatively, one might assume that the CP in question only constitutes a weak phase. However, these are stipulations necessary just to get around the problem (see note 8).

In short, SR cannot be characterized as a movement of the embedded subject to the matrix [Spec, $\mathrm{v}^{*}$ ]. Then, what kind of alternative analysis is available that is compatible with the PIC?

As an attempt to answer this question, I will make a crucial reference to the $\mathrm{C}-\mathrm{to}-\mathrm{V}$ incorporation. More specifically, I propose in this article that the SR in Japanese is a movement, in one fell swoop, to the Spec of the matrix VP, and that such an A-movement across the CP-boundary is possible because in the relevant configuration, the embedded $\mathrm{C}$ is incorporated to the matrix $\mathrm{V}$, whereby making the latter a variant of functional categories to which an EPP feature can be assigned. The Cto- $\mathrm{V}$ incorporation is independently motivated by a set of facts about indeterminate pronoun binding. It is also argued that the mechanism of C-to-V incorporation enables us to account for the fact that the SR construction results in lower acceptability when the embedded clause has a temporal reference independent of the matrix clause. 
This article is organized as follows: section 2 summarizes alleged evidence that the embedded subject in the SR construction must occupy a matrix object position in LF. Section 3 presents a set of data which appear to show that the embedded subject in question must be in the embedded clause throughout the derivation. In section 4 , we will resolve the apparent contradiction by proposing that the C-to- $\mathrm{V}$ incorporation occurs in the SR construction. In section 5, we will propose a new analysis of SR that is compatible with the PIC, and also attribute the limited possibility of long-distance A-movement to the Minimal Link Condition and a certain assumption on the EPP feature checking. In section 6, we will discuss both supporting evidence and potential problems with the proposed analysis. In section 7, we will discuss the restrictions on the temporal interpretation of the embedded clause. And section 8 is a conclusion.

\section{Evidence for Raising to the Matrix Clause}

Lasnik and Saito (1991) provide several pieces of evidence that, in the RTO in English, the embedded subject is raised to the matrix object position. The data is related to Binding Theory. Consider, first, the contrast in (5):

( 5 ) a. $* \mathrm{He}_{\mathrm{i}}$ loves Bob's $\mathrm{s}_{\mathrm{i}}$ mother.

b. John believes [he $\mathrm{i}_{\mathrm{i}}$ is a genius] even more fervently than Bob's $s_{i}$ mother does.

c.?*John believes [him $\mathrm{i}$ to be a genius] even more fervently than Bob's $s_{i}$ mother does.

(Lasnik and Saito (1991: 327-328))

(5a) is ill-formed since $B o b$ is c-commanded by the coindexed pronoun in the subject position, in violation of the Binding Condition (C). By contrast, $(5 b)$ is well-formed since the name here is contained in the adverb modifying the matrix clause and is not c-commanded by the pronoun in the embedded subject position. The ill-formedness of $(5 \mathrm{c})$ shows that the coindexed pronoun, which is the underlying subject of the embedded infinitive clause is raised out of it and moved to some Aposition in the matrix clause, and A-binds the name. Since there is good reason to believe that Binding Condition (C) applies to the LF representation, the raising must apply no later than LF.

The contrast in (6) leads us to the same conclusion:

(6) a. The DA accused the defendants $s_{i}$ during each other's $s_{i}$ tri- 
als.

b.?*The DA proved [that the defendants $s_{i}$ were guilty] during each other's $s_{i}$ trials.

c. ?The DA proved [the defendants ${ }_{i}$ to be guilty] during each other's $s_{i}$ trials.

(Lasnik and Saito (1991: 328))

(6a) is acceptable because the reciprocal each other is c-commanded by the coindexed NP in the object position in its binding domain, which is the matrix clause here. (6b) is unacceptable since the embedded subject does not c-command the reciprocal, which is contained in the adverb modifying the matrix clause, and Binding Condition (A) is violated. Although (6c) is not perfectly well-formed, it is significantly better than (6b). Lasnik and Saito (1991) argue that this is because the embedded subject of the infinitive clause undergoes RTO and occupies the matrix object position, at the point where Binding Condition (A) applies. If Chomsky (1995) is correct in assuming that Binding Condition (A) applies to the LF representation, the fact that $(6 \mathrm{c})$ is essentially well-formed also leads us to the conclusion that the embedded subject of the ECM complement occupies the matrix object position at LF.

Sakai (1996, 1998a) argues that the same diagnostics showing that the subject of the ECM complement undergoes RTO can apply to the Japanese counterparts and show that the embedded subject of the SR construction occupies the matrix object position at LF. Consider (7):

( 7 ) a. *Rie-wa kare $_{i}-\mathrm{o}$ Takasi $_{i}$-zisin yori tuyoku Rie-Top he-Acc Takasi-self than strong sinzi-tei-ru.

believe-Stat-Nonpast

'Rie believes him more strongly than Takasi (himself) does.'

b. Rie-wa kare $_{i}$-ga muzitu da to Takasi ${ }_{i}$-zisin yori Rie-Top he-Nom innocent Cop Comp Takasi-self than tuyoku sinzi-tei-ru.

strong believe-Stat-Nonpast

'Rie believes that he is innocent more strongly than Takasi himself does.'

c.?*Rie-wa kare $_{\mathrm{i}-\mathrm{O}}$ muzitu da to Takasi $\mathrm{i}_{\mathrm{i}}$ zisin yori

Rie-Top he-Nom innocent Cop Comp Takasi-self than tuyoku sinzi-tei-ru.

strong believe-Stat-Nonpast 
'Rie believes him to be innocent more strongly than Takasi himself does.'

(Sakai (1998a: 487))

The fact that (7c) is almost as degraded as (7a) and contrasts with (7b) shows that $(7 \mathrm{c})$ violates Binding Condition (C), because the embedded subject in (7c) occupies the matrix object position at LF.

The data relevant to Binding Condition (A) also makes the same point:

( 8 ) a. Rie-wa karera ${ }_{i}-\mathrm{o}$ otagai $i_{i}$-no syougen-niyotte

Rie-Top they-Acc each other-Gen testimony-based on sinzi-tei-ru.

believe-Stat-Nonpast

'Rie believes them based on each other's testimony.'

b.?*Rie-wa karera ${ }_{i}$-ga muzitu da to otagai ${ }_{i}$-no

Rie-Top they-Nom innocent Cop Comp each other-Gen

syougen-niyotte sinzi-tei-ru.

testimony-based on believe-Stat-Nonpast

'Rie believes that they are innocent based on each other's testimony.'

c. Rie-wa karera $\mathrm{i}_{\mathrm{i}} \mathrm{O}$ muzitu da to otagai $\mathrm{i}_{\mathrm{i}}$-no

Rie-Top they-Nom innocent Cop Comp each other-Gen syougen-niyotte sinzi-tei-ru.

testimony-based on believe-Stat-Nonpast

'Rie believes them to be innocent based on each other's testimony.'

(Sakai (1998a: 487))

The fact that $(8 \mathrm{c})$ is as acceptable as (8a) and contrasts with (8b) shows that $(8 \mathrm{c})$ satisfies Binding Condition $(\mathrm{A})$, because the embedded subject in (8c) occupies the matrix object position at LF.

The diagnosis using quantifier scope also suggests that, in the very context where the embedded subject in English undergoes RTO, the one in Japanese undergoes SR. Consider, first, the contrast in (9):

( 9 ) a. Some teacher scolded every student. (ambiguous)

b. Some teacher believes every student is intelligent.

(some $>$ every $/ *$ every $>$ some)

c. Some teacher believes every student to be intelligent.

(ambiguous) (Wilder (1997: 426))

In (9a), the universal quantifier in the direct object position can take the inverse scope with respect to the existential quantifier in the subject position. Thus, (9a) can have the interpretation in which each member of the set of students was scolded by a different teacher. This is due 
to the application of Quantifier Raising (QR) that takes the universal quantifier to a position c-commanding the quantificational subject at LF. The inverse scope interpretation is unavailable in (8b). This is because the operation of $\mathrm{QR}$ is clause-bound: it cannot move a quantifier across a clause-boundary. However, in spite of this restriction, the inverse scope reading is available in (9c). This is because the embedded subject of the ECM complement undergoes RTO and moves to the matrix clause before it undergoes QR.

Kuno (1976) observes that, in Japanese, the embedded clause with the Nominative subject and the SR construction with the Accusative subject also manifest a similar contrast with respect to quantifier scope (cf. also Tanaka (2002: 638)):

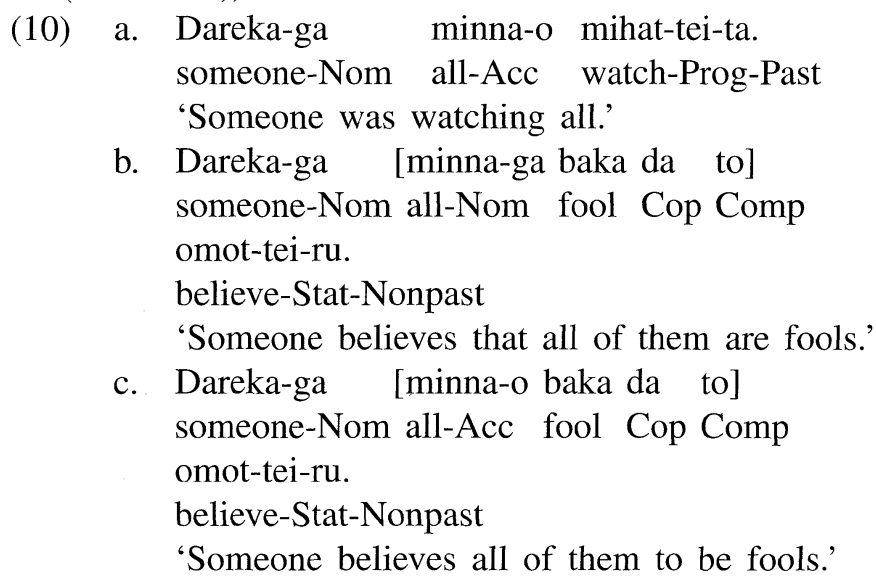

(Kuno (1976: 27-28))

In (10a), but not in (10b), the universal quantifier c-commanded by the existential quantifier in the (matrix) subject position can take scope over it. And (10c) patterns with (10a) rather than (10b), which shows that the Accusative NP in the SR construction in Japanese occupies somewhere in the matrix clause at the point where QR applies to it.

\section{Evidence against Raising to the Matrix Clause}

In the previous section, we summarized a set of evidence showing that the embedded subject of the SR construction in Japanese must occupy the matrix object position at the level of LF, where Binding Conditions (A) and (C) apply and where quantifier scope is determined. These facts are exactly parallel to those observed in the RTO construc- 
tion in English.

However, the availability of SR in Japanese is somewhat surprising in view of the fact that it is a kind of A-movement across CP. Note that although Japanese allows both A-scrambling and $\mathrm{A}^{\prime}$-scrambling, Ascrambling across a finite CP is impossible (see Saito (1992: 76)):
a. ?Karera $\mathrm{i}_{-} \mathrm{O}$ otagai $\mathrm{i}_{-}$-no
sensei-ga $t_{\mathrm{i}}$ home-ta.
they-Acc each other-Gen teacher-Nom praise-Past
'*Them, each other's teacher praised.'
b. *Karera $\mathrm{i}_{\mathrm{i}} \mathrm{O}$ otagai $\mathrm{i}_{\mathrm{i}}$-no sensei-ga [John-ga $t_{\mathrm{i}}$
they-Acc each other-Gen teacher-Nom John-Nom
home-ta to] omot-tei-ru.
praise-Past Comp believe-Stat-Nonpast
'*Them, each other's teachers believe that John praised.'

On the other hand, the acceptability of (7c) and (8c) implies that SR is characterized as a legitimate instance of A-movement across a finite $\mathrm{CP}$ boundary. Then, what derives the contrast between the ill-formedness of scrambling in (11b) and the well-formedness of SR in (8c)?

Before tackling this problem, however, we will discuss in this section another set of examples that appear to show that the embedded subject of the SR construction in Japanese is not in the matrix clause, either in overt syntax or at LF, a fact that seems to undermine the conclusion we reached upon the observations in (7), (8), and (10).

Let us start by noting that in Japanese, indeterminate pronouns such as dare 'anyone,' nani 'anything' are allowed to serve as negative polarity items (NPI) when they are bound by the Q-particle mo and by a negative element:
(12)
a. Taro-wa nani-mo kawa-nakat-ta.
Taro-Top anything-Q buy-Neg-Past
'Taro did not buy anything.'
b. Dare-mo sono hon-o kawa-nakat-ta. anyone-Q that book-Acc buy-Neg-Past
'No one bought that book.'

When the Q-particle mo serves to fix the interpretation of the indeterminate pronoun as a NPI, it is not required to attach to the immediate right of it; $\mathrm{C}$ or $\mathrm{V}$ may be the host of it:
a. Taroo-wa nani-o
kai-mo si-nakat-ta.
Taroo-Top anything-Acc buy-Q do-Neg-Past
'Taroo did not buy anything.' 
b. Hanako-wa [Taroo-ga nani-o kat-ta to-mo] Hanako-Top Taroo-Nom anything-Acc buy-Past Comp-Q omowa-nakat-ta. think-Neg-Past

'Hanako did not think that Taroo bought anything.'

However, the 'floating' of the Q-particle is not unconstrained. Thus, when the subject is the indeterminate pronoun, mo cannot attach to $\mathrm{V}$ :

(14) *Dare-ga warai-mo si-nakat-ta. anyone-Nom laugh-Q do-Neg-Past

'Anyone did not laugh.'

With respect to the syntactic relation between an indeterminate pronoun and the Q-particle mo, Kishimoto (2001) proposes that the former must be in the scope of the latter, and that the scope of $m o$ is defined by the notion of domain given in (15):

(15) $\mathrm{Y}$ is in the domain of a head $\mathrm{X}$ if it is contained in $\operatorname{Max}(\mathrm{X})$, where $\operatorname{Max}(\mathrm{X})$ is the least full-category maximal projection dominating $\mathrm{X}$.

This means that, when $m o$ is attached to $\mathrm{V}$ and no further operation applies, the scope of $m o$ is defined as the VP. ${ }^{4}$ If $\mathrm{V}$ undergoes head-

4 We are assuming with Kishimoto (2001) that the Q-particle mo is adjoined to an $\mathrm{X}^{0}$-category. In this respect, an anonymous reviewer points out, referring to Sakai (1998b) and Aoyagi (1998, 2006), that Q-particles in Japanese should be analyzed as being adjoined to an XP rather than $\mathrm{X}^{0}$ (see Kuroda (1965) for the original attribution of this proposal). However, as far as I can see, the gist of both Sakai's and Aoyagi's proposals is that focus particles (and also Q-particles) do not head a functional projection that selects VP and is selected by $\mathrm{T}$ but are adjuncts to VP (or $\mathrm{vP}$ ) that do not affect the selectional relation between $\mathrm{T}$ and $\mathrm{VP} / \mathrm{vP}$, and hence their proposals seem fully compatible with the assumption that they are adjoined to $\mathrm{V}^{0}$ rather than VP (cf. Aoyagi (1998: 28; note 9)). In fact, there is at least one piece of evidence showing that the Q-particles can be adjoined to an $\mathrm{X}^{0}$-level category. Note that $m o$ can be attached to both conjuncts of a verb coordination:

( i ) Taro-wa dare-o home-mo sikari-mo si-nak-atta.

Taro-Top anyone-Acc praise-Q scold-Q do-Neg-Past

'Taro did not either praise or scold anyone.'

Here, the sequence home-mo sikari-mo must be an instance of coordination of nonfinite verbs (i.e. $\mathrm{V}^{0}$ ), as in (iia), rather than VPs (see also Takano (2004)); otherwise, we would have to assume that (i) involves coordination of VPs out of which dare-o 'anyone-Acc' is extracted in an across-the-board fashion, as in (iib). Given the analysis in (iib), (i) would be ruled out since the NPI is not contained in Max(mo), which is VP according to the definition in (15): 
movement to $\mathrm{v}$, the scope of $m o$ is extended up to vP. Kishimoto assumes that in Japanese, $\mathrm{V}$ is overtly raised to $\mathrm{v}$, but not to a higher functional head, such as T. Therefore, the scope of mo in (14) is fixed as vP. (14) is then ruled out because the NPI, base-generated in [Spec, v], is overtly moved to [Spec, T] and gets out of the scope of mo (cf. Kuroda (1988) and Fukui (1986), among others, for the predicate-internal subject hypothesis).

The above explanation is justified by the following contrast:

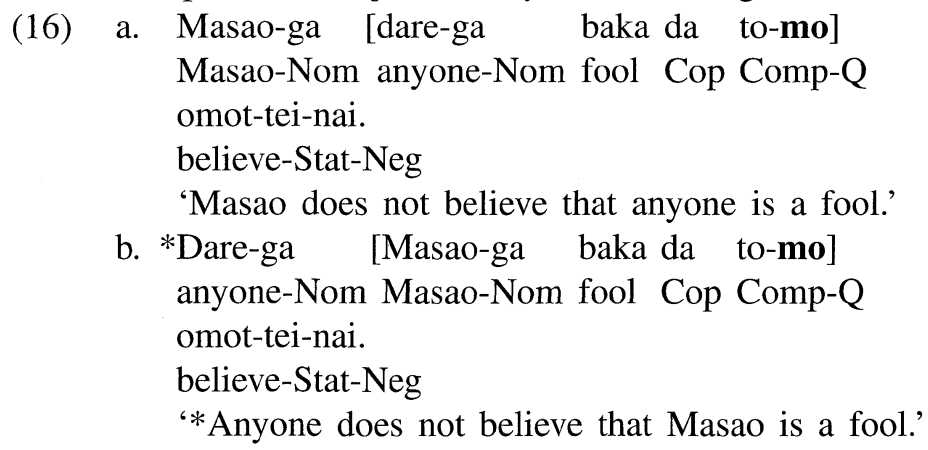

In both (16a) and (16b), since $m o$ is attached to the embedded $C$, the scope of mo should be the embedded CP. (16a) is ruled in because the indeterminate pronoun dare-ga 'who-Nom' is the embedded subject, which is in the scope of mo. (16b) is ruled out because dare-ga in (16b) is the matrix subject, which can never be in the scope of mo.

With these as presupposed, let us consider the SR construction in (17):

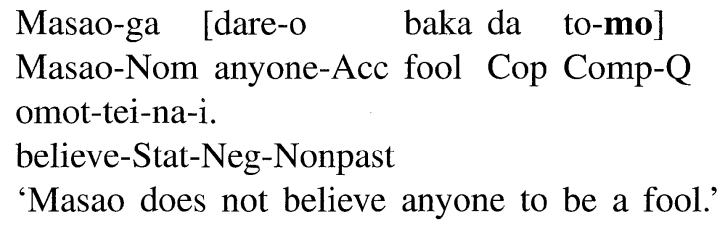

(Sakai (1998a: 489))

In (17), the embedded subject in the Accusative Case is the indeterminate pronoun. If the argument in the previous section is justified, it occupies the matrix object position in LF, and hence, it should be out-

(ii ) a. [vp dare-o [ $\mathrm{v}^{0}$ home-mo sikari-mo]]
b. *[XP dare- $\mathrm{O}_{\mathrm{i}}[\mathrm{vP}[\mathrm{vP}$ home]-mo [ve sikari]-mo] X]

This in turn suggests that at least some Q-particles can be adjoined to $\mathrm{V}^{0}$. 
side the scope of $m o$, at least in LF. Nevertheless, (17) is well-formed. Here arises a problem.

Sakai (1996, 1998a) argues that, in (17), the trace of the raised NPI being left in the embedded clause suffices for the NPI to be licensed by the Q-particle. However, such an argument is not on the right track. Note first that, in (14), the subject originates in [Spec, v] and is raised to [Spec, T], leaving a trace (or copy) in the base-generated position. The trace is in the scope of mo. However, (14) is ill-formed. ${ }^{5}$

Note also that the indeterminate pronoun cannot be moved out of the scope of mo by LF-movement, either. Consider, first, (18):
a. *Taroo-ni nani-ga
uta-e-mo si-na-i.
Taroo-Dat anything-Nom sing-can-Q do-Neg-Nonpast
'Taroo cannot sing anything.'
b. Hanako-ni-wa [Taroo-ni nani-ga
Hanako-Dat-Top Taroo-Dat anything-Nom
uta-e-ru to-mo] omo-e-nakat-ta.
sing-can-Nonpast Comp-Q think-can-Neg-Past
'Hanako could not think that Taroo could sing anything.'

Showing on independent grounds that the Nominative objects in (18a, b) are inside vP in overt syntax, ${ }^{6}$ Kishimoto (2001) assumes that they are "covertly" raised to the checking domain of T (Koizumi (1994), Takezawa (1987)). As a result of the LF-movement, nani-ga 'anything-

5 Sakai (1996: 199) provides, as a support for his assumption, the following example using scrambling (cf. also Sakai (1998a: 490)):

( i ) Dono gakusei-o $\mathrm{O}_{\mathrm{i}}$ sono sensei-ga [ $t_{\mathrm{i}}$ home-yooto-mo] si-nai. any student-Acc that teacher-Nom praise Comp-Q do-Neg 'For every $\mathrm{x}, \mathrm{x}=$ student, that teacher does not try to praise $\mathrm{x}$ '

In (i), an NP containing the indeterminate pronoun is raised out of the scope of mo by scrambling. Sakai judges this example as perfectly acceptable. To my ear, however, (i) is far worse than (17) and sounds almost as awkward as (14) or (16b). Kishimoto (2001: 605) also shows that the indeterminate pronoun must be bound by the Q-particle in overt syntax, using the following example:
(ii )?*Dare-o ${ }_{i} \quad$ Taroo-wa $t_{\mathrm{i}}$ home-mo si-nakat-ta. anyone-Acc Taroo-Top admire-Q do-Neg-Past '*Anyone, Taroo did not admire.'

If my judgment and Kishimoto's are sustained, the acceptability of (17) suggests that the embedded subject itself, rather than just its trace, must be in the scope of mo, both in overt syntax and at LF.

${ }^{6}$ Kishimoto (2001: 609-623) makes this point by means of a constraint on 'double focusing' by sae 'even.' 
Nom' goes out of the scope of $m o$, which is vP here. Hence, (18a) is ruled out. By contrast, (18b) is ruled in because even after the LF movement of nani-ga to the checking domain of $\mathrm{T}$, it still remains in the scope of mo, which is the embedded $\mathrm{CP}$ here.

In short, the indeterminate pronoun that acts as a NPI must be in the scope of the Q-particle mo, not only in overt syntax but also at LF; the kind of chain-binding Sakai (1996, 1998a) claims is not applicable here.

Applying this conclusion to (17), we are forced to say that the embedded subject of the SR construction in Japanese cannot move out of the embedded CP, either in overt syntax or in LF. However, this conclusion clearly contradicts the one we reached in view of Binding Theory and scope.

One might note that anaphor binding, coreference, and quantifier scope differ from NPI licensing in that the former three are phenomena in which the embedded subject of the SR construction acts as the 'binder' of something else, whereas the latter is a phenomenon in which the embedded subject must be licensed by binding by the Q-particle. On the basis of this asymmetry, one might argue that the Accusative subject raises to the matrix clause when it acts as the binder, whereas it does not when it acts as the 'bindee.' This stipulation might resolve the contradicting situation at hand.

However, that this is not an appropriate step to take is shown by the data in which the embedded subject acts as the 'binder' and the 'bindee' simultaneously. Consider, first, $(19 \mathrm{a}, \mathrm{b})$ :

$$
\begin{aligned}
& \text { a. Boku-wa [dare-ni soitu }{ }_{\mathrm{i}} \text {-no syasin-o mise-mo] } \\
& \text { I-Top anyone-Dat he-Gen picture-Acc show-Q } \\
& \text { si-nak-atta. } \\
& \text { do-Neg-Past } \\
& \text { 'I did not show anyone his picture.' } \\
& \text { b. *Soitui-no hahaoya-ga [dare }{ }^{-} \text {-O sikari-mo] } \\
& \text { he-Gen mother-Nom anyone-Acc scold-Q } \\
& \text { si-nak-atta. } \\
& \text { do-Neg-Past } \\
& \text { '*His mother didn't scold anyone.' }
\end{aligned}
$$

(19a) shows that the indeterminate pronoun in the indirect object position can be licensed as the NPI and be licensing the bound pronoun soitu 'the man/he' at the same time. It is licensed as the NPI since it is in the scope of the Q-particle attached to V; it can license the bound pronoun since the former c-commands the latter. (19b) is ill-formed 
since the bound pronoun in the subject NP is not c-commanded by the indeterminate pronoun in $\mathrm{vP}$.

With this in mind, consider the contrast in (20):
a. Taro-wa [dare $\mathrm{i}_{\mathrm{i}} \mathrm{O}$ kasikoi to mo] soitu $\mathrm{i}_{\mathrm{i}}$-no
Taro-Top anyone-Nom smart Comp-Q he-Gen
gendou-kara kanzi-nak-atta.
speaks and behaves-from feel-Neg-Past

'Taro didn't feel anyone to be smart, based on his speech and behavior.'

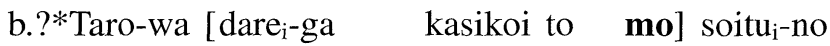

Taro-Top anyone-Nom smart Comp-Q he-Gen

gendou-kara kanzi-nak-atta.

speaks and behaves-from feel-Neg-Past

'Taro didn't feel that anyone is smart, based on his speech and behavior.'

In both (20a) and (20b), if the indeterminate pronoun remains in the embedded clause, it does not c-command the bound pronoun in the matrix adjunct and the latter is left unlicensed. On the other hand, if the indeterminate pronoun is raised, it is taken outside the scope of mo. In short, the two requirements cannot be met at the same time, in both (20a) and (20b). It would be predicted that both (20a) and (20b) are equally ill-formed. However, the fact is that (20a) is well-formed, whereas (20b) is degraded.

To resolve the paradox, we must elaborate a mechanism in which the Accusative subject is raised out of the embedded clause and nevertheless, it is not yet taken out of the scope of mo.

\section{The C-to-V Incorporation in the SR Construction}

As a solution to the above mentioned problem, in this section I claim that the head of the complement CP in the SR construction in Japanese undergoes incorporation to the verb in the matrix clause.

Kishimoto (2001) demonstrates that there is a case in which the indeterminate pronoun, which appears not to be in the scope of the Q-particle in overt syntax, is still licensed by it. Consider (21a, b):
a. Taroo-wa dare-ni soodan-o si-mo
Taroo-Top anyone-Dat consultation-Acc
si-nakat-ta.
do-Q do-Neg-Past 


\section{'Taroo did not consult anyone.' \\ b. Taroo-wa dare-ni soodan-mo \\ Taroo-Top anyone-Dat consultation-Q \\ si-nakat-ta. \\ do-Neg-Past}

(ibid.: 624)

In (21a), dare-ni 'anyone-Dat' is the indirect object of the verb suru 'do.' Since mo is attached to the verb, the indeterminate pronoun is in the scope of mo. Hence, it is ruled in, for the same reason as (13a). On the other hand, in (21b), the Q-particle is attached to the verbal noun which is the direct object of suru. The relation between the indirect object dare-ni 'anyone-Dat' and the direct object NP appears to be identical to the relation between them in (22). (22) is unacceptable because the indirect object is not in the scope of the direct object. However, in contrast to (22), (21b) is acceptable:

(22) *Taroo-wa dare-ni hon-mo watasa-nakat-ta.

Taroo-Top anyone-Dat book-Q hand-Neg-Past

'Taroo did not hand a book to anyone.'

Kishimoto (2001) argues that (21b) is ruled in because the noun soodan 'consultation,' which is the direct object of suru, undergoes incorporation to the light verb (see Saito and Hoshi (2000) for an independent argument for the noun incorporation in the light verb construction). As a result of the noun incorporation and the V-raising to $\mathrm{v}$, the scope of the Q-particle extends to $\mathrm{vP}$, in which the indeterminate pronoun is contained. Hence, $(21 \mathrm{~b})$ is ruled in. ${ }^{7}$

Now, let us propose that, just as the noun incorporates to the selecting verb in the light verb construction, so the complementizer incorpo-

7 Kishimoto (2001) suggests that the noun incorporation in question takes place in LF. However, this assumption, which implies that the NPI in (21b) is not in the scope of $m o$ in overt syntax, would incorrectly rule out (21b) for the same reasons as example (ii) in note 5 . Note also the contrast between the well-formedness of (21b) and the ill-formedness of (i):

( i ) *Taroo-wa dare-ni sigoto-no soodan-mo si-nakat-ta.

Taroo-Top anyone-Dat job-Gen consultation-Q do-Neg-Past

'Taroo did not consult anyone on his job.'

The presence of a Genitive case-marked argument of the verbal noun in (i) shows that the noun here has not been overtly incorporated to the light verb $s u$ 'do' (Saito and Hoshi (2000)). Hence, we assume that the NPI must be in the scope of mo both in overt syntax and at LF. Then, we are led to claim that the noun incorporation in (21b) takes place before Spell-Out. 
rates to the selecting verb in the SR construction. Given the $\mathrm{C}$-to- $\mathrm{V}$ incorporation and the subsequent $\mathrm{V}-\mathrm{to}-\mathrm{V}$ raising, the scope of mo necessarily extends up to the matrix vP. As a result, even after the embedded subject has undergone SR, it is still kept inside the scope of mo. Suppose that the landing site of the raised subject is the matrix [Spec, V] (see the next section for an argument for this nonstandard analysis). Suppose also that the simple operation of Merge is preferred over the more complex operation of Move (Chomsky (2000: 101-102)). Then, the (partial) structure of (20a) is schematized as in (23):

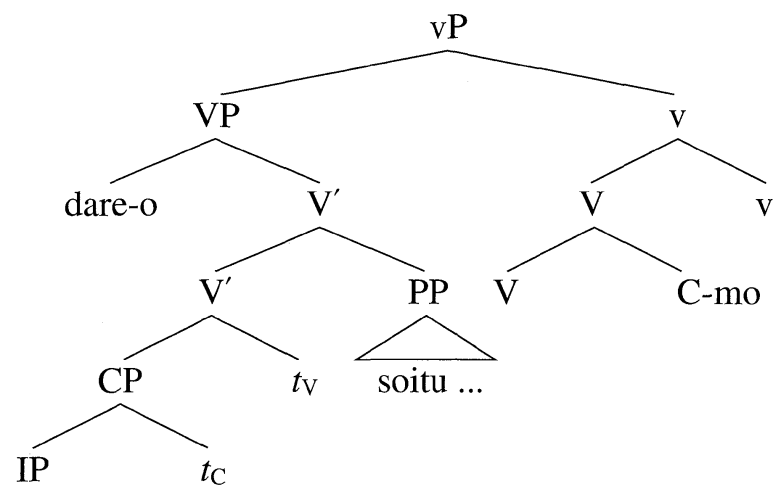

In (23), dare-o is dominated by $\mathrm{vP}$, which is $\operatorname{Max}(\mathrm{mo})$. Hence, the NPI is licensed. Since dare-o c-commands soitu in the adjunct PP adjoined to a projection of the matrix $\mathrm{V}$, the bound pronoun is also licensed by the indeterminate pronoun. Therefore, (20a) is ruled in. On the other hand, in (20b), such a movement of the embedded subject is prohibited because it has Nominative Case checked in the embedded clause. Note that $[\mathrm{Spec}, \mathrm{V}]$ is a position for Accusative Case checking, and movement of an NP whose Nominative Case has been checked to a position where Accusative Case can be checked violates the principle of Last Resort. In the absence of Subject Raising, the relevant structure of (20b) is (24). In (24), the NPI is licensed by mo since the former is in the scope of the latter. However, the indeterminate pronoun does not c-command the bound pronoun in the matrix adjunct PP, and the latter is left unlicensed. This is why (20b) is ruled out. 
(24)

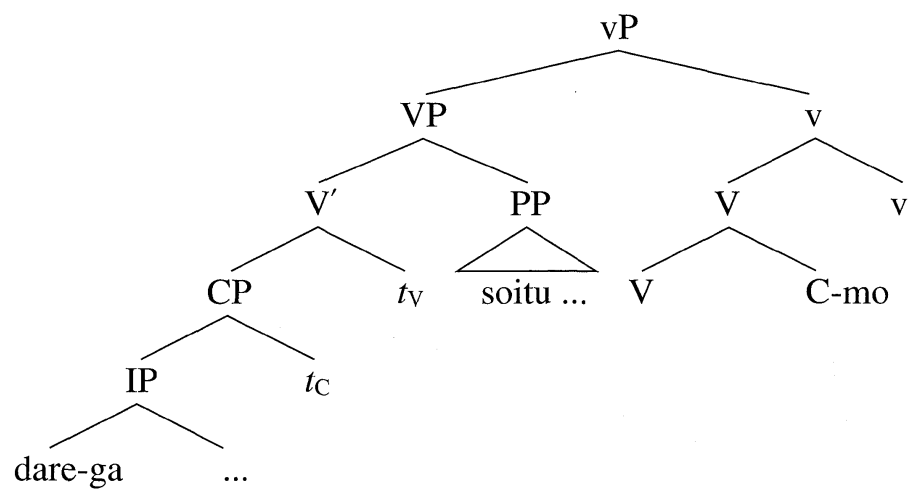

In short, given the hypothesis that the embedded $\mathrm{C}$ in the SR construction undergoes incorporation to the matrix $\mathrm{V}$, we can account for the otherwise mysterious behavior of the Accusative indeterminate pronoun as an NPI in the embedded subject position.

\section{The Derivation of Subject Raising and Its Restrictions}

We have justified the hypothesis that the embedded C in the SR construction undergoes incorporation to the matrix V. Now, let us return to the question we presented at the outset of this article, that is, why the SR can cross the CP boundary. This question is actually two-fold: first, we must answer why the A-movement from inside the embedded IP to the matrix object position in one fell swoop does not violate the PIC; second, why the A-movement that crosses the CP-boundary is possible in the SR construction but not elsewhere, even in Japanese (recall the ill-formedness (11b)). Since these questions are essentially independent of each other, we will take them apart and tackle, first, the question about the PIC.

We simply assumed in the previous section that the landing site of $\mathrm{SR}$ is [Spec, V] in the matrix clause. Since this movement crosses a CP-boundary without using [Spec, C], one might wonder if such a movement does not violate the PIC. Given Chomsky's (2000) formulation of the PIC, as stated in (3), such a derivation inevitably violates the condition.

However, Chomsky (2001) proposes a modification of Chomsky's (2000) PIC, as in (25):

(25) $\mathrm{Ph} 1$ is interpreted/evaluated at the next relevant $\mathrm{Ph} 2$.

(ibid.: 13) 
This means that, in the hypothetical structure in (26), where $\mathrm{H}$ is a phase head, the PIC introduces an important distinction between when $\mathrm{Z}$ is also a phase head and when $\mathrm{Z}$ is not a phase head:

(26) $[\mathrm{ZP} \mathrm{Z} \ldots[$ [HP $\alpha$ [H YP]]] ( $\mathrm{H}=$ a phase head $)$

When $\mathrm{Z}$ is also a phase head, $\mathrm{Z}$ cannot access the domain YP. However, when $Z$ is not a phase head, such as $T$, the probe $T$ can access an element of the domain YP inside HP; the PIC imposes no restriction on this.

Assuming (25), let us see how the derivation of SR proceeds (the angle-bracketed elements in (27) are copies of the moved elements):

a. NP raising and $\mathrm{V}$-raising in the embedded TP:

[тP NP [ $\left.\left.\mathrm{T}^{\prime}\left[\mathrm{vP}<\mathrm{NP}>\left[\mathrm{v}^{\prime}[\mathrm{vP} \ldots<\mathrm{V}>\ldots] \mathrm{V}+\mathrm{v}\right]\right] \mathrm{T}\right]\right]$

b. merger of the embedded $\mathrm{C}$ and TP:

[CР [TP NP [ $\left.\left.\left.\mathrm{T}^{\prime}\left[\mathrm{vP}<\mathrm{NP}>\left[\mathrm{v}^{\prime}[\mathrm{vP} \ldots<\mathrm{V}>\ldots] \mathrm{V}+\mathrm{v}\right]\right] \mathrm{T}\right]\right] \mathrm{C}\right]$

c. merger of the matrix $\mathrm{V}$ and $\mathrm{CP}$ and $\mathrm{C}-$ to- $\mathrm{V}$ incorporation:

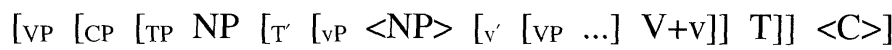
$\mathrm{C}+\mathrm{V}]$

Suppose that, after the derivation proceeds up to $(27 \mathrm{c})$, the matrix $\mathrm{v}^{*}$ is merged with the VP. Then, the matrix $\mathrm{v}^{*}$ cannot have its phi-features checked against the embedded Accusative NP, since it cannot look into the domain of the strong phase head $\mathrm{C}$, and the derivation crashes. ${ }^{8}$ However, let us propose that, when the embedded $\mathrm{C}$ is incorporated to the matrix $\mathrm{V}$, the matrix $\mathrm{V}$, which is a lexical category per se, turns nondistinct from a functional category. Let us also assume that, although a bona-fide lexical category cannot agree with or attract anything, a functional category can do so. This means that the $\mathrm{C}+\mathrm{V}$ complex can have an EPP-feature to attract a relevant NP. Note also that given (25), at the point of $(27 \mathrm{c})$, the head $\mathrm{V}$, which is not a phase head, can probe into the complement of the embedded $\mathrm{C}$. Therefore, the Accusative NP in the embedded [Spec, T] can be attracted to the matrix

${ }^{8}$ Chomsky $(2000,2001)$ assumes that the vP phase is divided into strong phase and weak phase, whereas CP always constitutes strong phase. This asymmetry between $\mathrm{CP}$ and $\mathrm{vP}$ is conceptually undesirable. Moreover, given (25), there is little reason to believe that there must be weak vP phase. Hence, we assume in this article that there is no distinction between strong and weak phases, and that $\mathrm{CP}$ and vP always constitute a strong phase. 
[Spec, V]. ${ }^{9}$ The step next to $(27 \mathrm{c})$ will then be $(27 \mathrm{~d})$ to $(27 \mathrm{f})$ :

(27) d. merger of the matrix adjunct PP with the matrix VP:

$\left[\mathrm{vP}\left[\mathrm{v}^{\prime}\left[\mathrm{CP}\left[\mathrm{TP} \mathrm{NP}\left[\mathrm{T}^{\prime}\left[\mathrm{vP}<\mathrm{NP}>\left[\mathrm{v}^{\prime}[\mathrm{vP} \ldots] \mathrm{V}+\mathrm{v}\right]\right] \mathrm{T}\right]\right]<\mathrm{C}>\right]\right.\right.$ $\mathrm{C}+\mathrm{V}] \mathrm{PP}]$

e. raising of the Accusative NP to the matrix VP:

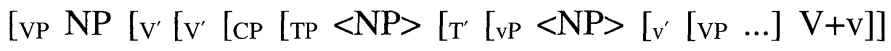
$\mathrm{T}]]<\mathrm{C}>$ ] $\mathrm{C}+\mathrm{V}] \mathrm{PP}]]$

f. merger of the matrix $\mathrm{V}^{*}$ and $\mathrm{VP}$ and $\mathrm{V}-$ to- $\mathrm{V}^{*}$ raising:

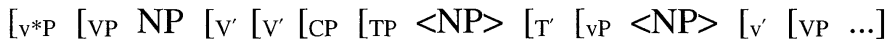

$\mathrm{V}+\mathrm{v}]] \mathrm{T}]]<\mathrm{C}>$ ] $<\mathrm{C}+\mathrm{V}>$ ] $\left.\mathrm{PP}]] \mathrm{C}+\mathrm{V}+\mathrm{v}^{*}\right]$

In (27d), the adjunct PP undergoes external merger with the matrix $\mathrm{VP}$, and in (27e), the Accusative NP undergoes A-movement from inside CP to the matrix [Spec, V]. This movement is not an improper movement, since it does not stop by the embedded [Spec, C] ${ }^{10}$ In (27e), the embedded subject occupies the higher Spec of the matrix VP, and hence it c-commands a coindexed anaphor in a matrix adjunct, satisfying Binding Condition (A) $(=(8 \mathrm{c})$ ), or c-commands a coindexed $\mathrm{r}$ expression in a matrix adjunct, inducing a Binding Condition (C) violation $(=(7 \mathrm{c}))$. Since the SR-ed NP in [Spec, V] is syntactically nondistinct from the direct object of a transitive verb, the SR-ed NP, if it is

9 The idea that RTO in English is a movement to the [Spec, V] in the matrix clause is independently developed in Johnson (1991), Bowers (2001), and Chomsky (2005). However, Koizumi (1993) and Tanaka (1999) propose different views about RTO (or object raising in general) in English. Whether RTO in English is a movement to [Spec, V] or not, it seems necessary to assume that it is not triggered by an EPP feature. Otherwise, we cannot account for the following contrast:

(i ) a. I've believed John for a long time now to be a liar.

b. *I've believed there for a long time now to be no solution to this problem.

(Kayne (1985))

${ }^{10}$ An anonymous reviewer points out that, while we have excluded movement from [Spec, C] to [Spec, V] (or [Spec, v]) as an instance of improper movement, we have resorted to the C-to-V movement, which is another instance of improper movement, according to $\mathrm{Li}$ (1990), and asks how we are to distinguish improper XP movement from improper $\mathrm{X}^{0}$-movement. However, Li's (1990) contention is to rule out the illegitimate instance of verb incorporation (VI), a V-to-I-to-C-to-V movement, as well as $\mathrm{A}^{\prime}$-movement of an XP followed by its A-movement, by Binding Condition (C). Binding Condition (C) does not itself prevent some XP which originates in an $\mathrm{A}^{\prime}$-position from moving to an A-position. In fact, Saito (1994) and Takano (2002) argue for the existence of a movement operation which takes an adjunct and adjoins it to an argument, which Takano calls 'oblique movement.' Arguably, the C-to- $\mathrm{V}$ movement is parallel to the oblique movement. 
a universal quantifier, can take scope over a quantifier in the matrix subject position $(=(9 c))$. Furthermore, in $(27 f)$, since the Accusative $\mathrm{NP}$ occupies the matrix [Spec, V], the matrix $\mathrm{v}^{*}$ can have its uninterpretable set of phi-features and Case feature checked against the NP via Agree, without violating the PIC.

Now, let us return to the second question put forward at the outset of this section: Why is the same A-movement to [Spec, V] unavailable in other environments such as in (11b)? If this were possible, since a further A-movement from the matrix [Spec, V] to the matrix IP-adjoined position (assumed to be an A-position) should be possible, the long-distance scrambled NP should A-bind an anaphor from the final landing site and $(11 \mathrm{~b})$ would be ruled in.

In relation to this matter, let us introduce Murasugi and Saito's (1994) observation that A-scrambling across a clause boundary is not always prohibited, but that it is permissible out of a control complement, which Chomsky (1981) assumes to be CP, as shown below:

(28) ?Karera $\mathrm{i}_{\mathrm{i}} \mathrm{-o}$ John-ga otagai $\mathrm{i}_{\mathrm{i}}$-no sensei-ni [PRO $t_{\mathrm{i}}$ they-Acc John-Nom each other-Gen teacher-to

homeru yooni] tanon-da.

praise to asked (Murasugi and Saito (1994: 310))

One might argue that a control complement is arguably not CP but IP (Bošković (1997), Ogawa (2001)), and hence the A-movement of karera-o does not violate the PIC. However, such a long-distance Amovement is not limited to a control complement. Takano (2002) observes that A-scrambling out of a finite clause boundary, which is normally impossible if the embedded subject is an overt NP in the Nominative Case, is rendered possible if the embedded subject is an empty pronoun (i.e. pro) bound by the matrix subject:

a. Dono sensei-ni-mo ${ }_{i}$ dareka-ga [Mary-ga $t_{\mathrm{i}}$ every teacher-Dat-also someone-Nom Mary-Nom ae-ru to] omot-tei-ru. meet-can Comp think-Stat-Nonpast 'Every teacher, someone thinks that Mary can meet.'

b. Dono sensei-ni-mo $\mathrm{i}_{\mathrm{i}}$ dareka-ga ${ }_{\mathrm{j}}\left[\mathrm{pro}_{\mathrm{j}} t_{\mathrm{i}}\right.$ ae-ru every teacher-Dat-also someone-Nom meet-can to] omot-tei-ru.

Comp think-Stat-Nonpast (Takano (2002: 292)) 'Every teacher, someone thinks that he can meet.' In (29a), the universal quantifier that has undergone long-distance 
scrambling to the matrix clause cannot take scope over the existential quantifier in the matrix subject position. Saito (1992) argues that this is because $\mathrm{A}^{\prime}$-scrambling undergoes radical reconstruction at LF. However, in (29b), which is identical to (29a) except that the embedded subject is the empty pronoun bound by the matrix subject, the long-distance scrambled universal quantifier can take scope over the existential quantifier in the matrix subject position, even if the reading is perhaps not fully acceptable. Thus, (29b) patterns with (10c) rather than (10b) with respect to the inverse scope taking. Takano (2002) suggests that this is because "finite clauses with bound pro subjects share with control clauses properties relevant to determining the nature of scrambling out of them" (ibid.: 293).

$(29 a, b)$ are data related to quantifier scope. We can make the same point using anaphor binding. Consider (30):
a.?*Karera- $\mathrm{O}_{i}$ otagai $\mathrm{i}_{\mathrm{i}}$-no
sensei-ga [Mary-ga $t_{\mathrm{i}}$ sikaru

they-Acc each other-Gen teacher-Nom Mary-Nom scold

beki da to] it-ta.

should Cop Comp say-Past

'Them, each other's teachers told Mary should scold.'

b. ?Karera- $\mathrm{O}_{\mathrm{i}}\left[\text { otagai }_{\mathrm{i}}-\mathrm{no} \text { sensei-ga }\right]_{\mathrm{j}}\left[\right.$ pro $_{\mathrm{j}} t_{\mathrm{i}}$ imasugu they-Acc each other-Gen teacher-Nom right now sikaru beki da to] it-ta. scold should Cop Comp say-Past

'Them, each other's teachers told they should scold right now.'

In (30a), the pronoun karera-o 'they-Acc' is long-distance scrambled across the overt embedded subject Mary-ga 'Mary-Nom.' Since the movement cannot be qualified as A-movement, the sentence is ruled out in violation of Binding Condition (A). By contrast, in (30b), the pronoun is moved across the bound pro subject and the sentence is acceptable. This also shows that the long-distance scrambling across the embedded subject pro bound by the matrix subject counts as A-movement, even if it crosses a finite clause boundary.

Combining these facts, we propose the following generalization:

(31) A-movement out of a clause-boundary is not possible if the embedded clause has a Nominative Case-marked subject in it.

In what follows, we will seek to explain why the generalization (31) holds. The basic idea that is used to account for this generalization is 
that whether the attracted element is phonologically overt or not is essential for the checking of the EPP feature.

Let us first consider the derivation of (11b) and (30a). Their structure at the point when the $\mathrm{C}$ is incorporated to $\mathrm{V}$ is represented in (32):

(32) $\left[\mathrm{vP}\left[\mathrm{cP}\left[\mathrm{TP}\right.\right.\right.$ NP-Nom $\left[\mathrm{T}^{\prime}\left[\mathrm{v}^{*} \mathrm{p}\right.\right.$ NP-Acc $\left[\mathrm{v}^{\prime}<\mathrm{NP}-\mathrm{Nom}>[\mathrm{vP}<\mathrm{NP}-\right.$ Acc $><\mathrm{V}>$ ] $\mathrm{V}+\mathrm{V}^{*}$ ]] $\left.\left.\mathrm{T}\right]\right]<\mathrm{C}>$ ] $\left.\mathrm{C}+\mathrm{V}\right]$

In (32), the Accusative NP is located at the edge of the embedded $\mathrm{v}^{*} \mathrm{P}$, the Nominative NP is raised to the embedded [Spec, T], and the $\mathrm{C}+\mathrm{V}$ complex is assigned an EPP feature that needs to be checked in accordance with the condition in (33): ${ }^{11}$

(33) $\mathrm{K}$ attracts $\mathrm{F}$ if $\mathrm{F}$ is the closest feature that can enter into a checking relation with a sublabel of $\mathrm{K}$.

(Chomsky (1995: 297))

Recall here that, in Japanese, $v$ does not move to T. Therefore, [Spec, $\mathrm{v}]$ and $[\mathrm{Spec}, \mathrm{T}]$ in the embedded clause are not equidistant from the matrix $\mathrm{V}$, and the closest $\mathrm{NP}$ to be attracted by the $\mathrm{C}+\mathrm{V}$ complex in (32) is the Nominative NP. If the Accusative NP cannot be attracted to the matrix [Spec, V], it cannot undergo A-movement to the matrix IPadjoined position, either. ${ }^{12}$ Hence, (11b) violates the Binding Condition (A) at LF.

Next, consider the derivation of (30b), which minimally differs from (30a) in that the embedded subject is not a Nominative NP but pro. The structure of $(30 \mathrm{~b})$ at the point when the embedded $\mathrm{T}$ is merged with the embedded $\mathrm{VP}$ is represented in (34a):

(34) a. [TP [vP pro $\left[\mathrm{v}^{\prime}[\mathrm{vP}\right.$ NP-Acc $\left.\left.\left.<\mathrm{V}>] \mathrm{V}+\mathrm{v}\right]\right] \mathrm{T}\right]$

Let us assume here that the EPP feature can only be checked by a phonologically visible category (cf. Holmberg (2000), Takahashi (2001)). Then, in (34a), the EPP feature on $\mathrm{T}$ cannot be checked against the embedded subject, since it is pro, which is phonologically empty. Therefore, the $\mathrm{T}$ must attract to its Spec the next closest NP, which is the Accusative NP inside VP. Subsequently, the embedded C is

11 A relevant definition is given below: If $\beta$ c-commands $\alpha$ and $\tau$ is the target of raising, then:

( $\mathrm{i}) \quad \beta$ is closer to $\mathrm{K}$ than $\alpha$ unless $\beta$ is in the same minimal domain as (a) $\tau$ or (b) $\alpha$ (cf. Chomsky (1995: 356))

12 More accurately, it would be better to assume that the landing site of A-scrambling is the outer Spec of TP (cf. Miyagawa (2001) and Kuroda (1988)). The crucial point is that A-scrambling is triggered by the EPP feature on T. 
merged with the TP, the matrix $\mathrm{V}$ is merged with the embedded $\mathrm{CP}, \mathrm{C}$ to- $\mathrm{V}$ incorporation takes place, and we obtain (34b):

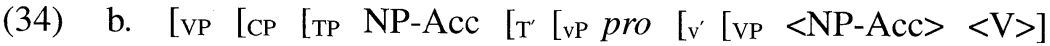
$\mathrm{V}+\mathrm{v}]] \mathrm{T}]]<\mathrm{C}>$ ] $\mathrm{C}+\mathrm{V}$ ]

In (34b), if the $\mathrm{C}+\mathrm{V}$ complex is assigned an EPP feature, it must attract to its Spec the closest overt element, which is the Accusative NP here. Hence, the Accusative NP is successfully carried into the matrix clause. Once it occupies the matrix [Spec, V], nothing prevents A-scrambling from there to the matrix IP-adjoined position. This is why (30b) satisfies Binding Condition (A).

To sum up, once we assume the $\mathrm{C}$-to- $\mathrm{V}$ incorporation and the assignment of an EPP feature to the $\mathrm{C}+\mathrm{V}$ complex, the generalization in (31) is explained by the definition of Attract in (33) and the assumption that an EPP feature must be checked by a phonologically visible element. ${ }^{13}$

\section{SR and C-to-V Incorporation as Overt Syntactic Movements}

We have argued that the SR construction in Japanese involves overt syntactic movement of the Accusative NP to the matrix [Spec, V] and the overt $\mathrm{C}$-to- $\mathrm{V}$ incorporation, as shown in (27). ${ }^{14}$

The proposal that the SR is an overt syntactic operation is motivated by the following observation made in Kuno (1976):

(35) Yamada-wa Tanaka-o/*Tanaka-ga orokanimo
Yamada-Top Tanaka-Acc/*Tanaka-Nom foolishly
tensai da to omot-tei-ta.
genius Cop Comp believe-Stat-Past

'Foolishly, Yamada believed Tanaka to be a genius.'

13 If a (successive cyclic) movement to [Spec, C] is also triggered by the EPP feature on $\mathrm{C}$, we need to assume that the EPP feature on $\mathrm{C}$ is distinct in nature from that on $\mathrm{T}$ or the $\mathrm{C}+\mathrm{V}$ complex and is sensitive not (only) to the phonological status of the attracted element but to some operator feature on it; otherwise, null operators could not move to [Spec, C], and no movement of a non-subject to [Spec, C] would be possible, since, in the absence of v-to-T movement, [Spec, T] is always closer to $\mathrm{C}$ than any element in $\mathrm{vP}$.

14 Note that we are not claiming that every instance of A-movement across CPboundary observed cross-linguistically is supported by the mechanism of C-to-V incorporation. Thus, a different mechanism may well be at work in extraction out of subjunctive complements (cf. Kayne (2000: 233), Ishii (2006)) or a wide variety of superraising phenomena (cf. Ura (1994)). 
The adverb orokanimo 'foolishly' necessarily modifies the matrix predicate omotteiru 'believe' and the NP that precedes the adverb must be located in the matrix clause. Therefore, the fact that the embedded subject in (35) can be in the Accusative, but not Nominative, shows that the Accusative NP, but not the Nominative NP, can be raised to the matrix clause in overt syntax. ${ }^{15}$

The assumption that the $\mathrm{C}$-to- $\mathrm{V}$ incorporation takes place in overt syntax is also essential in our theory, since without this movement, $\mathrm{V}$ cannot be assigned an EPP feature that triggers the overt SR. However, given both the overt $\mathrm{C}-$ to- $\mathrm{V}$ incorporation and the overt SR to the matrix [Spec, V], it appears that the legitimate scrambling of the embedded clause in (36) cannot be simply analyzed as a result of the scrambling of the embedded CP. ${ }^{16}$

15 The adverb orokanimo 'foolishly' can occur in various positions before the embedded subject, as in (i):

( i ) a. Yamada-wa orokanimo Tanaka-o tensai da to omot-tei-ta.

b. Orokanimo, Yamada-wa Tanaka-o tensai da to omot-tei-ta.

This shows that the adverb, which is base-generated in a $\mathrm{V}^{\prime}$-adjoined position (cf. Bowers (2001)), can undergo scrambling rather freely. Importantly, this fact does not demonstrate that the Accusative NP optionally undergoes SR in overt syntax, as argued in Hiraiwa (2001). See also Tanaka (2002: 646-647) for arguments against Hiraiwa's Optional Raising Analysis.

${ }^{16}$ An anonymous reviewer points out that the contrast between (ia) and (ib) seems to provide a support for the simple analysis:

\section{( i ) a. *Taro-wa tensai da to Hanako-o omot-ta. \\ Taro-Top genius Cop Comp Hanako-Acc believe-Past \\ 'Taro believed Hanako to be a genius.'}

b. ?Taro-wa tensai da to Hanako-no-koto-o omot-ta.

Taro-Top genius Cop Comp Hanako-Gen-about-Acc believe-Past

It is true that, if the Accusative object in (ia) remains in the embedded CP (whereas the koto-NP in (ib) is base-generated in the matrix clause), only (ib) can be ruled out because a non-constituent is moved. However, our system can also account for the contrast between (ia) and (ib) by an independently necessary condition. Given that the raised Accusative NP is pronounced in the matrix clause and the complementizer is pronounced inside CP, (ia) would have to be derived by SR followed by the scrambling of the CP. Under such a derivation, the raised CP in (ia) contains an unbound trace of the moved Accusative NP. Thus, we can rule out only (ia) by the Proper Binding Condition (PBC). Recently, the $\mathrm{PBC}$ has been discarded in favor of Müller's (1998) Unambiguous Domination, as defined in (ii):

(ii ) In $\ldots\left[\begin{array}{llll}\alpha & \ldots & \beta & \ldots\end{array}\right], \alpha$ and $\beta$ cannot check the same kind of feature (outside $\alpha)$.

(ii) can also accommodate the ill-formedness of (ia), since we are assuming that 
(36)

[Taroo-o ii hito da to] watasi-wa kanzi-ta.

Taroo-Acc nice person Cop Comp I-Top feel-Past

'I felt Taroo to be a nice person.'

The necessity of the EPP feature checking implies not only that the NP is 'overtly' raised to the matrix object position but also that it is pronounced in the position, since EPP requires phonological matrix in the designated position. Given this claim, it follows that the constituent preposed across the matrix subject in (36) must be either VP or vP. If it is VP that is fronted, and if $\mathrm{V}$ is overtly raised to $\mathrm{v}$, but no further (Kishimoto (2001)), then the complementizer should be attached to the main verb, as in (37a). Alternatively, if $\mathrm{vP}$ is preposed, the preposed constituent should include both the complementizer and the verb, excluding the tense suffix, as in (37b). In either case, (36) should not be derived. However, the fact is that (36) is well-formed and both (37a) and (37b) are severely ill-formed:

$$
\begin{aligned}
& \text { a. }{ }^{*}[\text { Taroo-o } \text { ii hito da } \text { watasi-wa to-kanzi-ta. } \\
& \text { Taroo-Acc nice person Cop I-Top Comp-feel-Past } \\
& \text { b.**[Taroo-o ii hito da to kanzi] watasi-wa ta. } \\
& \begin{array}{rlll}
\text { Taroo-Acc nice person Cop Comp feel I-Top Past }
\end{array}
\end{aligned}
$$

We propose to interpret these data as resulting from a set of independently necessary morphological conditions, which probably hold across languages. First, suppose Pesetsky's (1991) "C-Peripherality Condition," which requires that a phonologically overt $\mathrm{C}$ be adjacent to a boundary of CP (ibid.: 40). ${ }^{17}$ (37a) violates this condition, since to, which should

both SR and scrambling are triggered by the EPP feature (see note 12). In short, the contrast between (ia) and (ib) does not provide a support for the hypothesis that the Accusative object remains (or is pronounced) in the embedded CP in overt syntax. In fact, the alternative view, which keeps the Accusative object inside the embedded CP in overt syntax, will have to abandon either the simplest version of 'derivation-by-phase' theory, which precludes the 'countercyclic' LF movement, or the assumption that the RTO is triggered by the EPP feature. As a result, we will lose an account of either the facts on the LF-side in (7) to (9) or of the generalization in (31), as exemplified by $(29 \mathrm{a}, \mathrm{b})$ and $(30 \mathrm{a}, \mathrm{b})$. For these reasons, we are going to adopt the relatively complex analysis of (36) that involves scrambling of the matrix VP/vP. See also note 18 .

17 Pesetsky (1991: 40) proposes this condition as a way not only to rule out incorporation of an overt complementizer to the selecting $\mathrm{V}$ (which he assumes to be typologically rare or non-existent (ibid.: 38), but also to derive the so-called 'Doubly-Filled Comp Filter': *XP C, where XP occupies the Spec of C and the heads of both XP and $\mathrm{C}$ have phonological features. 
occur to the immediate right of $d a$, actually occurs to the right of the matrix subject. Second, suppose that the tense morphology must be merged with the verb stem. Then, (37b) is ruled out because it violates this condition. On the other hand, (36) satisfies both of the morphological requirements on $\mathrm{C}$ and $\mathrm{T}$. In order to derive (36), it suffices to assume that it is VP, rather than $\mathrm{vP}$, that is fronted here, ${ }^{18}$ and that the head $\mathrm{C}$, although it is syntactically incorporated to the matrix $\mathrm{V}$ and overtly carried along to $\mathrm{v}$, is pronounced at the tail of the chain created by the head movement, in order to satisfy the morphological requirement on the overt complementizer. If we assume that $\mathrm{V}$ raised to $\mathrm{v}$ is pronounced at $\mathrm{v}$ in Japanese (though it may not be in other languages), it follows that the verb is not spelled out in the fronted VP in (36). In short, our solution given to (36) is based on the claim that a result of the overt syntactic movement can be 'masked' by pronouncing the tail of the created chain, if the movement is head movement, but not if it is triggered by the EPP feature. ${ }^{19}$

18 An anonymous reviewer points out that, along these lines of reasoning, we will have to admit that a sentence like (i) could be derived by moving either the embedded $\mathrm{CP}$ or the matrix VP, and asks if the possibility of assigning more than one structural analysis to a single string does not cause a problem, in view of theoretical redundancy:

( i ) [Taroo-ga ii hito da to] watasi-wa kanzi-ta. Taroo-Nom nice person Cop Comp I-Top feel-Past

'I felt that Taroo was a nice person.'

In my view, however, it is not clear if this kind of ambiguity needs to be obliterated from grammar. Note that the surface word order of (ii) can also be given at least two different structural analyses, under the NP-raising analysis and the sentential subject analysis (cf. Sakai (1998a: 482-483)), but no one would argue that this state of affairs causes a problem of redundancy:

(ii ) Taroo-ga ii hito da to omow-are-ta.

Taroo-Nom nice person Cop Comp believe-Pass-Past

'Taroo was believed to be a nice person.' $O R$

'That Taroo was a nice person was believed.'

19 The assumption that head movement can take place in the absence of any morphological reflex may be independently necessary. Note that, in English, no adverb can intervene between the verb and its direct object NP (Pollock (1989)). Hence, if we adopt Chomsky's (1995) claim that the main V is overtly raised to $\mathrm{v}$, we need to assume that $\mathrm{V}$ is nevertheless pronounced in situ. 


\section{The Semantic Effects of the C-to-V Incorporation}

Chomsky (2000) claims that head movement occurs after Spell-Out, on the phonological branch of derivation (see Matushansky (2006) and references therein, for relevant discussions). The only argument Chomsky offers in favor of the PF treatment is that head movement does not seem to have any semantic import. On the other hand, we are claiming that the $\mathrm{C}-$ to- $\mathrm{V}$ incorporation, as an instance of head movement, takes place in overt syntax, although the movement is not phonetically reflected. Then, the most obvious way to defend our hypothesis seems to be to demonstrate that $\mathrm{C}-$ to- $\mathrm{V}$ incorporation does have a semantic effect. ${ }^{20}$ Indeed, we have already argued that, when

20 Pesetsky (1991) and Ohta (1997) have independently proposed the C-to-V incorporation in the RTO/SR construction. Although their proposals differ with respect to whether the incorporation takes place before S-structure (Pesetsky (1991) or in LF (Ohta (1997)), what they have in common is the idea that the C-to-V incorporation is the syntactic mechanism that embodies Chomsky's (1981) idea that 'S-bar deletion' takes place in the RTO construction, voiding the 'barrierhood' of the embedded CP for government of the embedded subject from the matrix $V$. However, neither of them provides evidence showing that the head movement has semantic effects. On the other hand, we have demonstrated that the C-to-V incorporation in the SR construction has the semantic effect of extending the scope of the Q-particle mo.

With this as presupposed, an anonymous reviewer points out that the data on Qparticles are not qualified as evidence for the phonetically unreflected C-to-V incorporation but are a mere puzzle that can be solved if we assume the incorporation; independent evidence for the proposal needs to be provided by showing that the SR construction is subject to general properties of head-movement, such as the Head Movement Constraint (HMC).

Although a conclusive argument along these lines is hard to establish, a contrast like the following arguably makes the point:

(i ) a. Taroo-wa Hanako-o yuuzai da to dantei-si-ta.

Taroo-Top Hanako-Acc guilty Cop Comp conclusion-do-Past

'Taroo concluded Hanako to be guilty.'

b. *Taroo-wa Hanako-o yuuzai da to dantei-o si-ta.

Taroo-Top Hanako-Acc guilty Cop Comp conclusion-Acc do-Past

In our system, (ia) is ruled in since the uninterpretable $\mathrm{V}$-feature of the embedded $\mathrm{C}$ can be checked off after it incorporates to the selecting $\mathrm{N}$ and the $\mathrm{C}+\mathrm{N}$ complex incorporates to the light verb, both in overt syntax. On the other hand, the verbal noun in (ib), which is followed by the Accusative case-marker, does not incorporate to the light verb in overt syntax (Saito and Hoshi (2000)). Hence, in order for the embedded $\mathrm{C}$ to check its uninterpretable $\mathrm{V}$-feature overtly, the $\mathrm{C}$ must incorporate to the light verb directly, skipping the intervening $\mathrm{N}$. This leads to a violation of the HMC. Hence, (ib) is ruled out. 
the Q-particle is attached to $\mathrm{C}$, the incorporation has the semantic effect of extending its scope to the matrix $\mathrm{VP} / \mathrm{vP}$. In this section, we will argue that a semantic effect is also observed in the absence of the Qparticle.

Let us start our discussion by noting the fact, originally observed in Kuno (1976) and extended in Ohta (1997), that the complement clause of the SR construction must be headed by a stative predicate in the nonpast tense:

$$
\begin{aligned}
& \text { a.??Baisinin-tati-wa sono otoko-o hannin dat-ta to } \\
& \text { juror-Pl-Top that man-Acc criminal Cop-Past Comp } \\
& \text { sinzi-tei-ru. } \\
& \text { believe-Stat-Nonpast } \\
& \text { 'Jurors believe that man to have been criminal.' } \\
& \text { b. *John-wa sono otoko-o nihon-ni ik-u 362)) } \\
& \text { John-Top that man-Acc Japan-to go-Nonpast Comp } \\
& \text { omot-ta. } \\
& \text { think-Past } \\
& \text { 'John thought that that man would go to Japan.' }
\end{aligned}
$$

In (38a) the embedded predicate is in the past tense and in (38b) the embedded predicate is an eventive predicate in the nonpast tense whose intended interpretation is that the event time of the embedded clause follows the event time referred to by the matrix predicate. Since all these examples turn out perfectly acceptable if the Accusative NP is replaced by the Nominative one, the incompatibility with the independent tense is a defining property of the SR construction. Even when the embedded clause has a stative predicate in the nonpast tense, it allows more than one temporal interpretation when the subject is in the Nominative Case, whereas the interpretation is disambiguated in the SR construction. Thus, (39a) means either that John thought Mary was in LA when he had the thought (the past-contemporaneous reading) or that John thought that Mary would be in LA at some time later than when he had the thought (the future shifted reading). By contrast, (39b), the SR construction, can only have the past-contemporaneous reading:

$$
\begin{aligned}
& \text { a. John-wa [Mary-ga (asu-wa) Rosu-ni } \\
& \text { John-Top Mary-Nom tomorrow-Top LA-in } \\
& \text { i-ru to] omot-ta } \\
& \text { exist-Nonpast Comp think-Past } \\
& \text { 'John thought that Mary was/would be in LA (tomorrow).' }
\end{aligned}
$$


b. John-wa [Mary-o (*asu-wa) Rosu-ni i-ru John-Top Mary-Acc tomorrow-Top LA-in exist-Nonpast to] omot-ta.

Comp think-Past

'John thought Mary to be in LA (*tomorrow).'

These facts demonstrate that the embedded clause of the SR construction cannot have an independent tense and its temporal reference must be dependent on that of the matrix clause (cf. Stowell (1982)).

Now, I propose that this temporal dependency of the embedded clause on the matrix clause in the SR construction is attributed to the presence of the C-to-V incorporation.

Note first that whether an embedded clause is finite or nonfinite is reflected on the morphology of the complementizer. Thus, in English, the clause introduced by that must be a finite clause, whereas the clause introduced by for must be an infinitive clause. For this reason, it is reasonable to assume that there is a relation between $\mathrm{C}$ and $\mathrm{T}$ with respect to temporal properties. I will implement this idea by assuming that, in every clause, the predicate has a temporal index, which identifies the temporal reference of the event or state denoted by the predicate, and that the index must be licensed by the closest c-commanding $\mathrm{T}$, through coindexing. Furthermore, let us propose that, if a clause has the projection of $\mathrm{CP}$, the $\mathrm{C}$ shares the temporal index with the selecting T (cf. Enç (1987)). These two proposals mean that, in a sentence like (40a), the embedded predicate pregnant shares the index $i$ with both the embedded $\mathrm{T}$ and the embedded $\mathrm{C}$, that, and independently, the matrix predicate heard shares the index $j$ with the matrix $\mathrm{T}$, as in $(40 \mathrm{~b})$ :

(40) a. John heard [CP that [TP Mary was pregnant]].

b. John $T_{j}$ heard $_{j}\left[\mathrm{CP}\right.$ that $\mathrm{t}_{\mathrm{i}}$ [TP Mary $\mathrm{T}_{\mathrm{i}}$ was pregnant $\left.\mathrm{t}_{\mathrm{i}}\right]$.

c. John $T_{j}$ that ${ }_{i}+h e a r d d_{j}\left[C P t_{i}\left[{ }_{T P}\right.\right.$ Mary $T_{i}$ was pregnant $\left.t_{i}\right]$.

Since in (40b), the embedded $\mathrm{T}$ and the matrix $\mathrm{T}$ have different indices, they can have independent temporal references. Therefore, the time at which he heard about Mary's pregnancy does not have to be identical to the time at which she is pregnant. This is why (40a) can have a shifted reading, according to which Mary's being pregnant is prior to John's hearing about it, which in turn is prior to the speech time.

Now, suppose that the $\mathrm{C}$ in the embedded clause undergoes incorporation to the matrix $\mathrm{V}$, as in (40c). In this case, the complex head $[\mathrm{V}$ $\mathrm{C}+\mathrm{V}]$ comes to have two indices, $i$ and $j$. Accordingly, the matrix $\mathrm{T}$ 
shares both indices. In this situation, if they referred to mutually distinct temporal points, it would result in interpretive anomaly, since a single $\mathrm{T}$ cannot have more than one temporal reference. Therefore, if the $\mathrm{C}-\mathrm{to}-\mathrm{V}$ incorporation takes place, the two indices must denote the same temporal points. In this case, (40a) has another reading, which Enç (1987) calls a simultaneous reading, according to which John hears at a past time that Mary is pregnant at the time of hearing. In other words, the relevant time for the complement clause is identical to the time where the matrix clause is evaluated. ${ }^{21}$

Given the impact of the $\mathrm{C}-\mathrm{to}-\mathrm{V}$ incorporation on the temporal interpretation of the embedded predicate, we are ready to explain the restriction on the temporal interpretation of the SR construction in Japanese. Suppose that the C-to- $\mathrm{V}$ incorporation takes place only when the functional category $\mathrm{C}$ has an uninterpretable $\mathrm{V}$ feature that needs to be checked against the matrix $\mathrm{V}$. If the embedded $\mathrm{C}$ did not have an uninterpretable $\mathrm{V}$ feature, it cannot be raised to the matrix $\mathrm{V}$. In this case, the matrix $\mathrm{V}$ remains a lexical category and cannot be assigned an EPP feature. Therefore, it cannot attract the embedded (Accusative) subject to its Spec. Given the PIC, the matrix $\mathrm{V}^{*}$ cannot attract it, either. It follows that the uninterpretable Case feature of the NP is left unchecked (or, unvalued) and the derivation crashes at LF. On the other hand, when the embedded $\mathrm{C}$ has an uninterpretable $\mathrm{V}$ feature, it must incorporate to the matrix $\mathrm{V}$ to check the feature against it. As a result of this incorporation, the temporal index on the embedded $\mathrm{C}$ must be identified with that of the matrix $\mathrm{T}$. Therefore, the embedded $\mathrm{T}$, which shares the same index with the embedded $\mathrm{C}$, cannot have independent temporal reference. The temporal restriction we observed in

${ }^{21}$ Our account of the simultaneous reading is different from that of Enç (1987). Enç claims that the embedded clause has the simultaneous reading if the embedded $\mathrm{T}$ is directly bound by the matrix $\mathrm{T}$, whereas a past shifted reading is obtained if the embedded $\mathrm{T}$ is anchored by the selecting $\mathrm{C}$, which in turn is bound by the matrix T.

As pointed out in Enç (1987), the simultaneous reading is not permitted when the complement clause is headed by a nonstative predicate, as in (i), or when the complement clause is headed by a non-past $\mathrm{T}$, as in (ii):

(i ) Mary found out that John failed the test.

(ii) John heard that Mary is pregnant.

We will not go into any issue arising from these facts, since they are irrelevant for our purposes. See Enç (1987) for relevant discussions. 
$(38 \mathrm{a}, \mathrm{b})$ and $(39 \mathrm{~b})$ is explained in this way. ${ }^{22}$

\section{Conclusion and Theoretical Implications}

In this article, I have proposed that, under certain morphological conditions, the embedded $\mathrm{C}$ can undergo syntactic incorporation to the selecting $\mathrm{V}$, and argued that the head movement has a couple of syntactic and semantic effects. On the syntactic side, we argued that Subject Raising (SR), as an A-movement across a CP boundary, does not violate the PIC, because the $\mathrm{C}-\mathrm{to}-\mathrm{V}$ incorporation makes it possible for the embedded subject to move to the Spec of the matrix VP. We also demonstrated that A-scrambling across a (finite) CP boundary in Japanese is permitted if the embedded clause has a PRO or pro subject, but not if it has a phonologically overt (Nominative) subject, and argued that such a difference between overt and covert subjects emerges because the EPP feature assigned to the $\mathrm{C}+\mathrm{V}$ complex must be checked by a phonologically visible element closest to it. On the semantic side, we demonstrated that the C-to- $\mathrm{V}$ incorporation has the effect of extending the scope of a Q-particle attached to the C-head. We also argued that the $\mathrm{C}$-to- $\mathrm{V}$ incorporation results in the establishment of a certain local relation between the matrix $\mathrm{T}$ and the embedded $\mathrm{C}$, whereby the temporal reference of the embedded $\mathrm{T}$ in the SR construction must be equated with that of the matrix $\mathrm{T}$.

To the extent that the proposals and arguments in this article are justified, they have a number of theoretical implications. First, given the syntactic and semantic effects of C-to- $\mathrm{V}$ incorporation, it is reasonable to conclude, contrary to Chomsky $(2000,2001)$, that (at least some

22 Ogawa (2001) argues, in line with Pesetsky (1991, 1995), that the phonetically empty $\mathrm{C}$ is an affix that needs to satisfy its morphological requirement by attaching to the closest c-commanding, phonologically overt, element. When the CP is at the complement of V, as in (i), the host of the affixation is the selecting V. However, in (i), the time at which John buys the car is clearly distinct from the time at which the speaker thinks about the proposition, which is the speech time:

( i ) I think [CP $\phi_{\mathrm{C}}$ [IP John bought the car]].

In order to get around this problem, we assume that what incorporates to the matrix $\mathrm{V}$ in (i) is only its formal and phonological features, and its semantic features, including the temporal index, are left in situ. See Holmberg (2000) for the proposal that certain movements can carry only phonological features, leaving formal and semantic features in situ. See also note 19. 
instances of) head movement can take place in syntax rather than on the PF branch of derivation. Second, as far as A-movement to the matrix [Spec, V] is justified as a way to move across a CP-boundary, we do not have to divide CP into strong and weak phases, and we can maintain the simplest assumption that all the CPs are strong phases. Third, we claimed that the EPP feature assigned to $\mathrm{T}$ or $\mathrm{V}$ can only be checked by a phonologically overt element. Since this claim implies that a phonologically empty subject, such as PRO or pro, may not move out of the vP in which it is base-generated (cf. Baltin (1995)), it follows that, in a sentence with such a subject, [Spec, T] can be used as an escape hatch for the A-movement of a non-subject. Arguably, this mechanism may be generalized to account for the so-called "restructuring" phenomena observed across languages, without assuming the literal movement of the embedded $\mathrm{V}$ to the matrix $\mathrm{V}$. Each of these theoretical implications needs to be carefully examined in future research.

\section{REFERENCES}

Aoyagi, Hiroshi (1998) "Particles as Adjunct Clitics," NELS 28, 17-31.

Aoyagi, Hiroshi (2006) Nihongo-no Zyoshi to Kinou Hantyuu (Case-Particles and Functional Categories in Japanese), Hituzi Syobo, Tokyo.

Baltin, Mark (1995) "Floating Quantifiers, PRO, and Predication," Linguistic Inquiry 26, 199-248.

Bobaljik, Jonathan D. (1999) "A-Chains at the Interfaces: Copies, Agreement and 'Covert' Movement," ms., McGill University.

Bošković, Željko (1997) The Syntax of Nonfinite Complementation: An Economy Approach, MIT Press, Cambridge, MA.

Bowers, John (2001) "Predication," The Handbook of Contemporary Syntactic Theory, ed. by Mark Baltin and Chris Collins, 299-333, Blackwell, Malden, MA.

Chomsky, Noam (1981) Lectures on Government and Binding, Foris, Dordrecht.

Chomsky, Noam (1995) The Minimalist Program, MIT Press, Cambridge, MA.

Chomsky, Noam (2000) "Minimalist Inquiries: The Framework," Step by Step: Essays on Minimalist Syntax in Honor of Howard Lasnik, ed. by Roger Martin, David Michael and Juan Uriagereka, 89-155, MIT Press, Cambridge, MA.

Chomsky, Noam (2001) "Derivation by Phase," Ken Hale: A Life in Language, ed. by Michael Kenstowicz, 1-52, MIT Press, Cambridge, MA.

Chomsky, Noam (2005) "On Phase," ms., MIT.

Enç, Mürvet (1987) "Anchoring Conditions for Tense," Linguistic Inquiry 18, 
633-657.

Fukui, Naoki (1986) A Theory of Category Projection and Its Applications, Doctoral dissertation, MIT.

Hiraiwa, Ken (2001) "Multiple Agree and the Defective Intervention Constraint in Japanese," ms., MIT.

Holmberg, Anders (2000) "Scandinavian Stylistic Fronting: How Any Category Can Become an Expletive," Linguistic Inquiry 31, 445-484.

Ishii, Toru (2006) "On the Relaxation of Intervention Effects," WH-Movement Moving On, ed. by Lisa Cheng and Norvert Corver and forwarded by Noam Chomsky, 217-246, MIT Press, Cambridge, MA.

Johnson, Kyle (1991) "Object Positions," Natural Language \& Linguistic Theory 9, 577-636.

Kaneko, Yoshiaki (1988) "On Exceptional Case-marking in Japanese and English,” English Linguistics 5, 271-294.

Kawai, Michiya (2006) "Raising to Object in Japanese: A Small Clause Analysis," Linguistic Inquiry 329-339.

Kayne, Richard (1985) "Principles of Particle Constructions," Grammatical

Representation, ed. by Jacquline Guéron, Hans-Georg Obenauer and JeanYves Pollock, 101-142, Foris, Dordrecht.

Kayne, Richard (2000) Parameters and Universals, Oxford University Press, New York.

Kishimoto, Hideki (2001) "Binding of Indeterminate Pronouns and Clause Structure in Japanese," Linguistic Inquiry 32, 597-634.

Koizumi, Masatoshi (1993) "Object Agreement Phrases and the Split VP Hypothesis," MIT Working Papers in Linguistics 18: Papers on Case and Agreement I, 99-148.

Koizumi, Masatoshi (1994) "Nominative Objects: the Role of TP in Japanese," MIT Working Papers in Linguistics 24: Formal Approaches to Japanese Linguistics 1, 211-230.

Kuno, Susumu (1976) "Subject Raising," Syntax and Semantics 5, 17-49.

Kuroda, Shige-Yuki (1965) Generative Grammatical Studies in Japanese, Doctoral dissertation, MIT. [Published by Garland, New York, 1979.]

Kuroda, Shige-Yuki (1988) "Whether We Agree or Not: A Comparative Syntax of English and Japanese," Linguisticae Investigationes 12, 1-47. [Reprinted in Japanese Syntax and Semantics: Collected Papers, ed. by S.-Y. Kuroda, 315-357, Kluwer, Dordrecht, 1992.]

Lasnik, Howard and Mamoru Saito (1991) "On the Subject of Infinitives," CLS 27, 324-343.

Li, Yafei (1990) " $\mathrm{X}^{0}$-Binding and Verb Incorporation," Linguistic Inquiry 21, 399-426.

Matushansky, Ora (2006) "Head Movement in Linguistic Theory," Linguistic Inquiry 37, 69-110.

Miyagawa, Shigeru (2001) "The EPP, Scrambling, and Wh-in-situ," Ken Hale: A Life in Language, ed. by Michael Kenstowicz, 293-338, MIT Press, 
Cambridge, MA.

Müller, Gereon (1998) Incomplete Category Fronting, Kluwer, Dordrecht.

Murasugi, Keiko and Mamoru Saito (1994) "Adjunction and Cyclicity," WCCFL 13, 302-317.

Ogawa, Yoshiki (2001) A Unified Theory of Verbal and Nominal Projections, Oxford University Press, New York.

Ohta, Kaoru (1997) "Tense in the Subject Raising Construction," Japanese/ Korean Linguistics 6, 353-368.

Ormazabal, Javier (1995) The Syntax of Complementation: On the Connection between Syntactic Structure and Selection, Doctoral dissertation, University of Connecticut.

Pesetsky, David (1991) "Zero Syntax II: An Essay on Infinitives," ms., MIT.

Pesetsky, David (1995) Zero Syntax: Experiencers and Cascades, MIT Press, Cambridge, MA.

Pollock, Jean-Yves (1989) "Verb Movement, Universal Grammar, and the Structure of IP," Linguistic Inquiry 20, 365-424.

Postal, Paul (1974) On Raising: One Rule of English Grammar and Its Theoretical Implications, MIT Press, Cambridge, MA.

Saito, Mamoru (1992) "Long-Distance Scrambling in Japanese," Journal of East Asian Linguistics 1, 69-118.

Saito, Mamoru (1994) "Additional-Wh Effects and the Adjunction Site Theory," Journal of East Asian Linguistics 3, 195-240.

Saito, Mamoru and Hiroto Hoshi (2000) "Japanese Light Verb Construction and the Minimalist Program," Step by Step: Essays on Minimalist Syntax in Honor of Howard Lasnik, ed. by Roger Martin, David Michaels and Juan Uriagereka, 261-295, MIT Press, Cambridge, MA.

Sakai, Hiromu (1996) "Clause Reduction in Japanese," MIT Working Papers in Linguistics 29: Formal Approaches to Japanese Linguistics 2, 193-212.

Sakai, Hiromu (1998a) "Raising Asymmetry and Improper Movement," Japanese/Korean Linguistics 7, 481-497.

Sakai, Hiromu (1998b) "Feature Checking and Morphological Merger," Japanese/Korean Linguistics 8, 189-201.

Stowell, Timothy (1982) "The Tense of Infinitives," Linguistic Inquiry 13, 561570.

Takahashi, Daiko (2001) "On the Nature of the EPP," ms., Tohoku University.

Takano, Yuji (2002) "Surprising Constituents," Journal of East Asian Linguistics 11, 243-301.

Takano, Yuji (2004) "Coordination of Verbs and Two Types of Verbal Inflection," Linguistic Inquiry 35, 168-178.

Takezawa, Koichi (1987) A Configurational Approach to Case Marking in Japanese, Doctoral dissertation, University of Washington.

Tanaka, Hidekazu (1999) "Raised Objects and Superiority," Linguistic Inquiry 30, 317-325.

Tanaka, Hidekazu (2002) "Raising to Object out of CP," Linguistic Inquiry 33, 
$637-652$.

Ura, Hiroyuki (1994) Varieties of Raising and the Feature-Based Bare Phrase Structure Theory, MIT Occasional Papers in Linguistics 7, Cambridge, MA.

Wilder, Chris (1997) "Phrasal Movement in LF: De re Readings, VP-ellipsis and Binding," NELS 27, 425-439.

Graduate School of Information Science

Tohoku University

6-3-09 Aramaki-aza-Aoba, Aoba-ku, Sendai

Miyagi 980-8579

ogawayo@mail.tains.tohoku.ac.jp 